\title{
Female Workers' Age and Position on Organizational Citizenship Behaviour: The Moderator Role of Organization-Based Self-Esteem
}

\author{
Meng-Shan Tsai \\ Department of Technology Application and Human Resource Development \\ National Taiwan Normal University \\ E-mail: teach3029@yahoo.com.tw \\ Chi-Cheng Chang \\ Department of Technology Application and Human Resource Development \\ National Taiwan Normal University \\ E-mail: samchang@ntnu.edu.tw
}

Received: February 29, 2012

doi:10.5296/jmr.v4i2.1462
Accepted: March 14, 2012 Published: April 1, 2012

URL: http://dx.doi.org/10.5296/jmr.v4i2.1462

\begin{abstract}
This study discusses the age and position of women in relation to elements of organizational citizenship behaviour (OCB) at Level 1, with organization-based self-esteem (OBSE) as the moderator and independent variable at Level 2. However, participation does not achieve an acceptable standard and is removed from this study. Study 1 and Study 2 employ a hierarchical linear model (HLM) to explore the influence of age and position on obedience and loyalty, respectively, where OBSE is the moderator. This study investigates 391 females from 12 occupations and uses 349 pieces of data to obtain the HLM. The results of Studies 1 and 2 show that age is positively related to obedience and position negatively and related to loyalty, but that OBSE is positively related to obedience, and the moderating effect of OBSE only appears in the relationship between position and obedience in Study 1. This study exclusively investigates females, and hopes to provide avenues relating to the effects of age and position on OCB of males and females in future research. Furthermore, the future research hopes to develop the path about OCB generation based on obedience, loyalty, and participation.
\end{abstract}


Keywords: Female, Age, Position, Organization-based self-esteem (OBSE), Organizational citizenship behaviour (OCB) 


\section{Introduction}

The female labour force has changed remarkable in the past century, and has been the subject of extensive of literature and theory. On the supply side, because in the past women's pay was lower and career paths were limited, they were excluded from or segregated within the labour market (Anker, 1997; Colley, 2011). On the demand side, employer preferred to employ men over women, even if women were equally qualified for a position, because employers considered that women had less commitment than men to stay at work (Colley, 2011). Furthermore, Chao (2011) demonstrated concrete evidence for the fact that there has been continuous improvement in women's positions, and achievements in terms of their empowerment, in all walks of life in both developed and developing countries. As reported above, previous studies have considered the female employment market, but have not took account of the effects of individual and organizational factors simultaneously on their behaviours within organizations, namely, this study considered that the occupations' characteristics could be included. Therefore, this study will fill this knowledge gap by presenting a hierarchical linear model (HLM). HLM can address individual and occupational levels simultaneously, and compensate for the shortcomings of other statistical methods.

\subsection{OCB and Female Workers}

Lovell et al. (1999) suggested women have a higher OCB score than men. Usually, researchers have measured OCB as a whole, however OCB consists of different concepts and should be considered individually. Therefore, this study aims to fill the knowledge gap by discussing women's obedience, loyalty, and participation within organizations.

\subsection{Age and Female Workers}

Colley (2011) considered the relationship between age and female labour force participation, but explained that the literature suggests age has only a weak link with female participation. Zacher et al. (2010) indicated that age is negatively associated with focus on opportunities. Therefore, older employees have fewer opportunities in the work context than younger employees. The above studies have clearly explained age and female workforce market and work opportunities, and this study explores whether women's ages influence their behaviour in an organization.

\subsection{Position and Female Workers}

In the US, only $16 \%$ of chief executives are women, and $13.6 \%$ of managerial positions in American Fortune 500 companies are held by women. In Taiwan, 16\% of managerial and administrative positions are held by women; this means that female political and economic status has been improved (Chao, 2011). Traditionally, women tend, more than men to, encounter the "glass cliff" in workplaces - that is, women in leadership positions have been associated with increased risk of negative consequences (Haslam \& Ryan, 2008; Ross-Smith $\&$ Huppatz, 2010). After considering the above research, it was felt by the authors that the subject of female workers is worth discussing.

Several researchers have studied organizational citizenship behaviour (OCB) in Taiwan, such 
as Tang and Tang (2011), Chiang and Hsieh (2012), and Liu (2009). Thus, OCB is an important research issue in Taiwan. Organization-based self-esteem (OBSE) refers to the degree to which organizational members believe that they can satisfy their demands by taking on roles within an organization (T. L. P. Tang \& Ibrahim, 1998). According to a study by Tang and Ibrahim (1998), OBSE is most strongly related to altruism and compliance with OCB. Moreover, Sekiguchi et al. (2008) proposed that the higher an individual's OBSE, the higher their motivation is with respect to $\mathrm{OCB}$, because they wish to be consistent with or enhance their positive self-views as being competent and valued within their organizations. However, they found that OBSE does not moderate the relationship between leader-member exchange (LMX) quality and OCB. Following the above studies, OCB was viewed as a variable. However, OCB consists of different concepts, so this study will discuss its elements and treated them as the dependent variables.

Based on cognitive consistency theory, which demonstrates that individuals are motivated to engage in behaviours, maintain attitudes, and perform behaviours that are consistent with their self-concept (Chen, Aryee, \& Lee, 2005; Van Dyne, Vandewalle, Kostova, Latham, \& Cummings, 2000). Van Dyne et al. (2000) cited the study by Korman, which described that individuals have higher self-esteem who are more likely to have positive attitudes, get involved, and contribute to the organization. In Van Dyne et al.'s (2000) study, they indicated that OBSE was influenced by dispositions and led to OCB as organizational members strive to maintain consistency between their beliefs and behaviours. Following the concepts of cognition, Soubelet (2011) showed that the significantly negative correlation between age and cognition. Therefore, increasing age correlated with a decrease in cognitive abilities.

LMX theory posits the quality of relationships between the leaders and their followers. Moreover, LMX relationship influences OCB motives. Followers perform higher OCB when LMX relationship has high quality. Additionally, high quality LMX relationship makes employees to engage in OCB. Furthermore, attribution theory proposes that one person's attributions for another person's behaviour are affected by their relationship with that person. Hence, positive leader attributions are related to $\mathrm{OCB}$, this provides motivation to engage in OCB with the goal to develop a high quality LMX relationship (Bowler, Halbesleben, \& Paul, 2010). Although past research has not explored the relationship between position and OCB, Bowler et al.'s (2010) study maybe pointed out this relationship. As theories above, this study considered that age, position (i.e. leaders and followers, managers and non-managers), and OBSE could predict OCB. What's more, this study build on the theoretical work by Chen et al. (2005) and Van Dyne et al. (2000), both studies treated OBSE as mediators and led to OCB. Thus, this study viewed OBSE as a moderator leading to OCB.

OCB has been categorized according to styles set forth by Organ and Graham. Organ used five dimensions to measure OCB, including altruism, courtesy, sportsmanship, civic virtue, and conscientiousness. Graham's categorization included organizational obedience, loyalty, and participation (Torlak \& Koc, 2007). Because this study discusses the effects of workers' age and position and OBSE on OCB, and to explore workers' behaviours within their occupations, Graham's categorization is used for this study. 
As found in previous literature (Chao, 2011; Colley, 2011; Lovell et al., 1999), age, position and OCB are correlated with female workers; OCB was related to OBSE, and OBSE was associated with position. Not a lot of studies explored the relationship between position and OCB, but individuals have different thoughts, attitudes, and behaviours with their age and position change. According to the above theories, past studies, and statements, this study uses age, position, OBSE, and OCB as the research variables, and explores the relationship among them.

\section{Aims and Hypotheses}

The aim of this study is to determine whether female workers' age and position can predict the extent of each of the three factors in Graham's OCB categorization (Torlak \& Koc, 2007; Van Dyne, Graham, \& Graham, 1994), and to examine the moderating effects of OBSE on the relationships between age and OCB and position and OCB.

Wagner and Rush (2000) proposed that age-dependent relationships as antecedent variables are related to OCB across the productive lifespan of employees. Additionally, they suggested that younger and older adults have different views with respect to self, others, and work. Hence, younger and older adults have different perspectives on OCB. As discussed above, age may predict obedience, loyalty, and participation. The following hypotheses are therefore proposed:

Hypothesis 1a: Age will be related to obedience.

Hypothesis 1b: Age will be related to loyalty.

Hypothesis 1c: Age will be related to participation.

Surprisingly, few studies have discussed the relationship between age and OBSE. Lapierre et al. (2009) indicated that when employees engage in OCB with their supervisors, supervisors are more likely to invest time and effort in employees. However, Lapierre et al.'s (2009) study did not explain the degree to which employees and supervisors engage in OCB. This study fills this knowledge gap, and demonstrates that position may influence obedience, loyalty, and participation. Additional hypotheses are therefore that:

Hypothesis 2a: Position will be related to obedience.

Hypothesis 2b: Position will be related to loyalty.

Hypothesis 2c: Position will be related to participation.

As noted in the introduction, OBSE is associated with altruism and compliance (T. L. P. Tang \& Ibrahim, 1998), and both are factors of OCB (Kim, 2006). Furthermore, Bowling et al. (2010) demonstrated that OBSE is positively related to OCB, with a correlation coefficient of .38. They also found that OBSE is a mediator of the effect of general self-esteem and OCB. Thus, OBSE may be a predictor of obedience, loyalty, and participation. We further propose that:

Hypothesis 3a: OBSE will be related to obedience. 
Hypothesis $3 b$ : OBSE will be related to loyalty.

Hypothesis 3c: OBSE will be related to participation.

Bowling et al. (2010) tested the relationship between OBSE and age, and the results showed that the correlation is significant. Moreover, task variety is a part of task complexity, and was found to be positively associated with OBSE; the reason for this is that task variety and complexity provide challenges to employees. Employees, especially middle managers, use their various skills effectively to be successful and achieve variety (Hui, Lee, \& Niu, 2010). Where an employee receives more pay than others in comparable positions, it enhances their self-perceived status within the organization and results in higher levels of OBSE (Gardner, Van Dyne, \& Pierce, 2004).

OBSE has been seen as a moderator in previous studies. For instance, Panaccio and Vandenberghe (2011) indicated that OBSE is a moderator of certain types of uncertainty on commitment, and moderates the relationships between role clarity, and commitment forms and to turnover intentions. As reported above, this study suggests that OBSE is a moderator of age and position in relation to the three elements of OCB. We therefore propose that:

Hypothesis 4a: OBSE will moderate the influence of age on obedience; the relationship between age and obedience will be stronger in occupations with higher levels of OBSE.

Hypothesis 4b: OBSE will moderate the influence of age on loyalty; the relationship between age and loyalty will be stronger in occupations with higher levels of OBSE.

Hypothesis 4c: OBSE will moderate the influence of age on participation; the relationship between age and participation will be stronger in occupations with higher levels of OBSE.

Hypothesis 5a: OBSE will moderate the influence of position on obedience; the relationship between position and obedience will be stronger in occupations with higher levels of OBSE.

Hypothesis 5b: OBSE will moderate the influence of position on loyalty; the relationship between position and loyalty will be stronger in occupations with higher levels of OBSE.

Hypothesis 5c: OBSE will moderate the influence of position on participation; the relationship between position and participation will be stronger in occupations with higher levels of OBSE.

Taken as a whole, the above hypotheses provide a conceptual model spanning two levels of analysis. Hypotheses 1a to 1c comprise a Level 1 model, which link the two individual-level variables. Hypotheses $2 \mathrm{a}$ to $2 \mathrm{c}, 3 \mathrm{a}$ to $3 \mathrm{c}, 4 \mathrm{a}$ to $4 \mathrm{c}$, and $5 \mathrm{a}$ to $5 \mathrm{c}$ comprise Level 2 models. The full model implied by these hypotheses is shown in Figure 1. Having presented the above hypotheses following the conceptualization of the levels at which the construct exists, we will now proceed to establish a series of nested HLM, which will test the above hypotheses. 


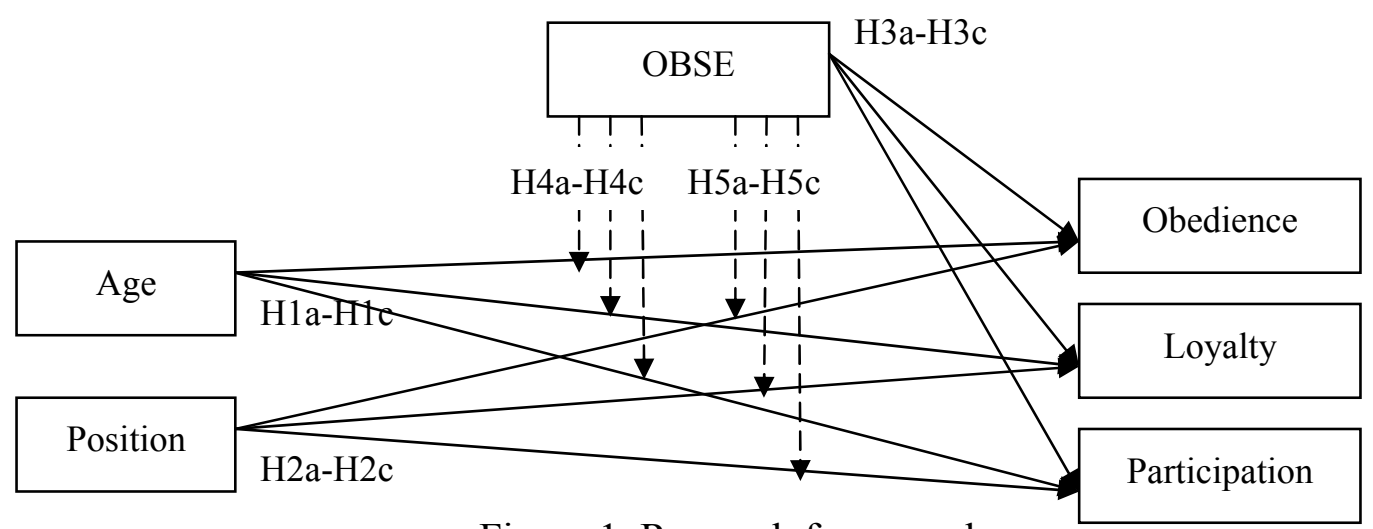

Figure 1. Research framework.

\section{Research Design}

\subsection{Data Collection}

A total of 391 surveys were distributed to workers in 12 different occupations in Taiwan. The participants were all female. About $61.3 \%$ of workers were aged from 21 to 40 years old, and $86.2 \%$ were non-managers. After removing responses for missing data, the sample was reduced to 349 , giving a response rate of $89.26 \%$.

\subsection{Measurements}

\subsubsection{OBSE}

OBSE is based on an employee's self-reflection of how their performance in an organization contributes to being a viable member of an organization (Kang, Twigg, \& Hertzman, 2010). OBSE also reflects an employee's belief in their capabilities and worth in an organization (Widmer, Semmer, Kälin, Jacobshagen, \& Meier, 2011). OBSE was measured in a study by Pierce et al. (1989), and was found to consist of 10 items. In the present study, a four-point Likert scale from 1 (= strongly disagree) to 4 (= strongly agree) was used, and the coefficient alpha was .895 for this scale. The reason for using a four-point scale was to avoid allowing the respondents to give a neutral answer, which would have caused bias to arise in the research results.

\subsubsection{Obedience}

Obedience can be demonstrated according to the degree of individuals' respect for organizational rules, regulations, and instructions, and the carrying out of tasks (Dimitriades, 2007; Torlak \& Koc, 2007). Eleven items were used to assess this variance, as in a study by Van Dyne et al.(1994). The respondents expressed their agreement using a four-point Likert scale ranging from 1 (= strongly disagree) to 4 (= strongly agree). The coefficient alpha was .855 for this scale.

\subsubsection{Loyalty}

Loyalty refers to identifying with the organization's leaders and the whole organization, defending the organization against threats, and transcending the benefits of individuals, work 
groups, and departments (Dimitriades, 2007; Torlak \& Koc, 2007). Loyalty was assessed using 12 items drawn from Van Dyne et al.(1994). It used a four-point Likert scale ranging from 1 (= strongly disagree) to 4 (= strongly agree), and the coefficient alpha was .804 for this scale.

\subsubsection{Participation}

Participation is concerned with organizational affairs and is characterized by involvement in organizational governance (Dimitriades, 2007; Torlak \& Koc, 2007). The scale of participation was assessed by 11 items drawn from Van Dyne et al. (1994). The scale used was a four-point Likert scale ranging from 1 (= strongly disagree) to 4 (= strongly agree), and the coefficient alpha was .842 for this scale.

\section{Results}

The means, standard deviations (SD), Cronbach's alphas and correlations are shown in Table 1. As can be seen from the table, no significant correlation exists between age and position. Because both were independent variables, this result indicated that the collinearity does not exist.

Table1. Descriptive statistics, reliability, and correlation

\begin{tabular}{llcccccccc}
\hline & & Means & SD & 1 & 2 & 3 & 4 & 5 & 6 \\
\hline 1. & Age $^{\mathrm{a}}$ & 2.792 & 1.113 & & .218 & -.093 & .495 & .417 & .035 \\
2. & Position $^{\mathrm{b}}$ & 1.992 & 0.873 & .087 & & .038 & .458 & -.010 & .268 \\
3. & OBSE & 30.522 & 4.867 & .077 & $-.158^{* *}$ & $(.895)$ & .555 & .242 & $.702^{*}$ \\
4. & Obedience & 34.425 & 4.428 & $.269^{* *}$ & -.059 & $.448^{* *}$ & $(.855)$ & .519 & $.645^{*}$ \\
5. & Loyalty & 32.803 & 4.797 & $.324^{* *}$ & -.070 & $.440^{* *}$ & $.384^{* *}$ & $(.804)$ & $.648^{*}$ \\
6. & Participation & 33.537 & 4.439 & $.201^{* *}$ & -.052 & $.587^{* *}$ & $.601^{* *}$ & $.601^{* *}$ & $(.842)$ \\
\hline
\end{tabular}

Note: Cronbach's alphas are given in parentheses on the diagonals. Individual-level correlations $(n=391)$ are below the diagonal, and occupation-level correlations $(n=12)$ are above the diagonal. ${ }^{*} p<.05,{ }^{* *} p<.01$. Two-tailed tests.

${ }^{\text {a }}$ Coded as $\leq 20$ years old, $1 ; 21-30,2 ; 31-40,3 ; 41-50,4 ; 51-60,5 ; \geq 61,6$.

${ }^{\mathrm{b}}$ Coded as manager, 1; non-manager, 2.

A hierarchical linear model (HLM) was used to conduct a multilevel variable analysis. Data appropriate for HLM must be nested in nature. Usually, the nested data contain at least two levels, in which entities at a lower level are nested within entities at a higher level (Gentry \& Martineau, 2010). Multilevel analyses were performed using HLM 6.0, which can simultaneously survey relationships within a level and between levels where other analytic tools cannot. Generally, HLM allows researchers to test relationships involving predictors at two or more levels, and outcome variable at the lowest level (Gavin \& Hofmann, 2002; Gentry \& Martineau, 2010).

The $r_{\mathrm{wg}(\mathrm{J})}$ represents the within-group index, and is the important index in HLM. The $\mathrm{r}_{\mathrm{wg}(\mathrm{J})}$ of OBSE, obedience, loyalty, and participation were $.995, .996, .996$, and .981 , respectively. On the other hand, ICC (1) represents the intraclass correlation coefficient, and ICC (2) refers to 
the reliability of the mean. With respect to obedience, loyalty, and participation, ICC (1) was $.063, .084$, and .047 , respectively. These values were well above the acceptable value of .059 , except for participation, which means that participation should be ignored. Hence, $\mathrm{H} 1 \mathrm{c}, \mathrm{H} 2 \mathrm{c}, \mathrm{H} 3 \mathrm{c}, \mathrm{H} 4 \mathrm{c}$, and $\mathrm{H} 5 \mathrm{c}$ were removed from this study. The ICC (2) values of obedience and loyalty were .959 and .970 , respectively.

\subsection{Study 1: Obedience as the Outcome Variable}

\subsubsection{Null Model}

In this study, obedience was the outcome variable and no predictors were specified for either Level 1 or 2 with regards to examining the significance level of the Level 2 residual variance of the intercept $\left(\tau_{00}=1.226, \chi^{2}=29.481, p=.002\right)$. Moreover, ICC (1) and ICC (2) of OBSE were .048 and .946 . The ICC (1) figure for obedience was .063 ; indicating that $6.3 \%$ of the variance in obedience resided between occupations, and $93.7 \%$ of the variance resided within occupations.

\subsubsection{Random Coefficient Model}

H1a and H2a predicted that individual age and position would be associated with individual workers' obedience. In this model, Level 1 contained age and position, with no predictors specified for Level 2. The two independent variables explained $24 \%$ of the within-occupation variance. As reported in Table 2 , age $\left(\gamma_{10}=0.889, p=0.018\right)$ and position $\left(\gamma_{20}=-2.461, p=\right.$ 0.015) had significantly positive and negative relationships with obedience, respectively. Therefore, H1a and H2a were supported.

Random effects were also tested. Using a chi-squared test to analyze the variance component of the intercept term $\left(\pi_{00}\right)$, the value was $1.526, \chi^{2}=27.249, p=.003$. This result meant that the null hypothesis was rejected, and the occupations varied significantly in terms of obedience at entry into the age and position. Furthermore, the slope terms of age $\left(\pi_{11}\right)$ and position $\left(\pi_{21}\right)$ were $0.573\left(\chi^{2}=15.863, p=.103\right)$ and $5.785\left(\chi^{2}=85.902, p=.000\right)$, respectively. For age, the null hypothesis was not rejected, and there was no significant variation. On the contrary, for position, the null hypothesis was rejected, and there was significant variation.

\subsubsection{Intercepts- and Slopes-as-Outcomes Model}

This model was used to examine H3a, H4a, and H5a. To test H3a, the HLM model was used where age and position were the Level 1 predictors and the intercept coefficients were obtained from Level 1 on the measures of the occupation-level OBSE at Level 2. Table 2 shows that the OBSE $\left(\gamma_{01}=5.673, p=0.004\right)$ had a significant relationship with obedience. Therefore, H3a was supported. To test H4a and H5a, the prerequisite was to confirm whether age and position were significantly related to obedience in the intercepts-as-outcomes model. 
According to Table 2, age $\left(\gamma_{10}=0.925, p=0.016\right)$ and position $\left(\gamma_{20}=-2.318, p=0.009\right)$ were significantly related to obedience. Thus, both cross-level interactions were tested. Table 2 indicates that OBSE moderated the relationship between position and obedience $\left(\gamma_{21}=13.876\right.$, $p=0.034)$, but not between age and obedience $\left(\gamma_{11}=3.490, p=0.254\right)$. Thus, H4a was not supported, but H5a was. The specified occupation-level variables accounted for $46 \%$ of the between-occupations variance in obedience. Because OBSE was the moderator between position and obedience, the interaction should be discussed. The results are shown in Figure 2, in which the horizontal axis represents position (manager and non-manager) and the vertical axis represents the obedience scores. The interaction demonstrates how the within-occupation relationship between position and obedience changes as a function of OBSE. The resulting model is shown in Figure 3.

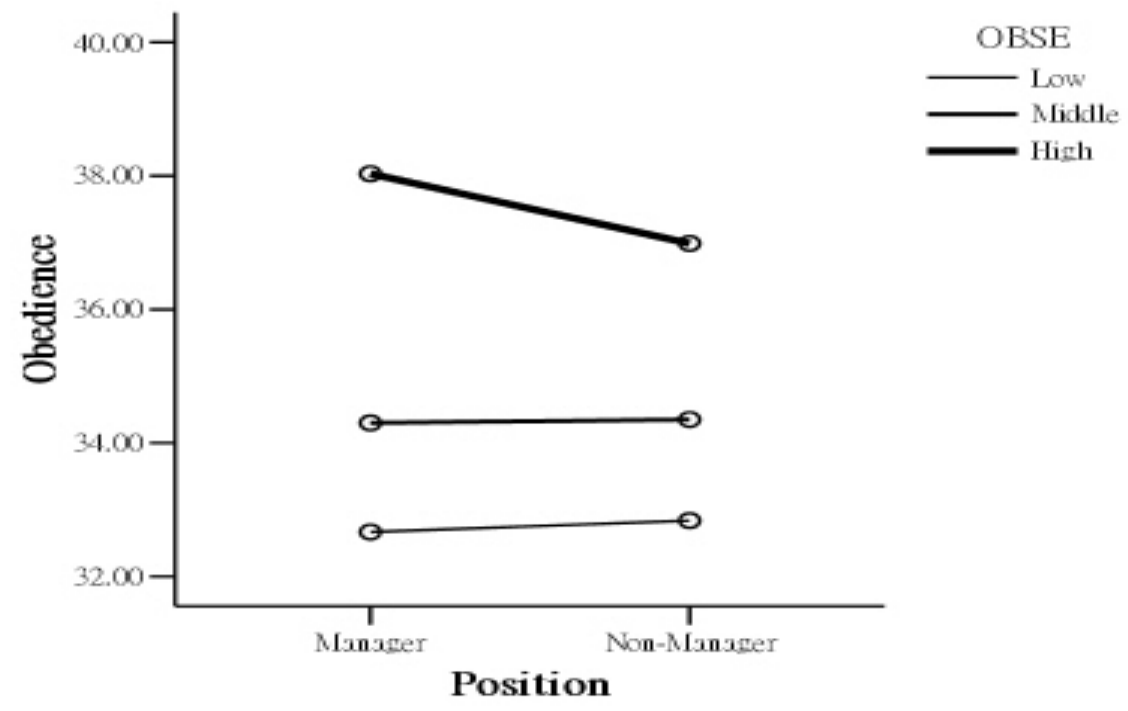

Figure 2. Interactive effects of position and OBSE in predicting obedience.

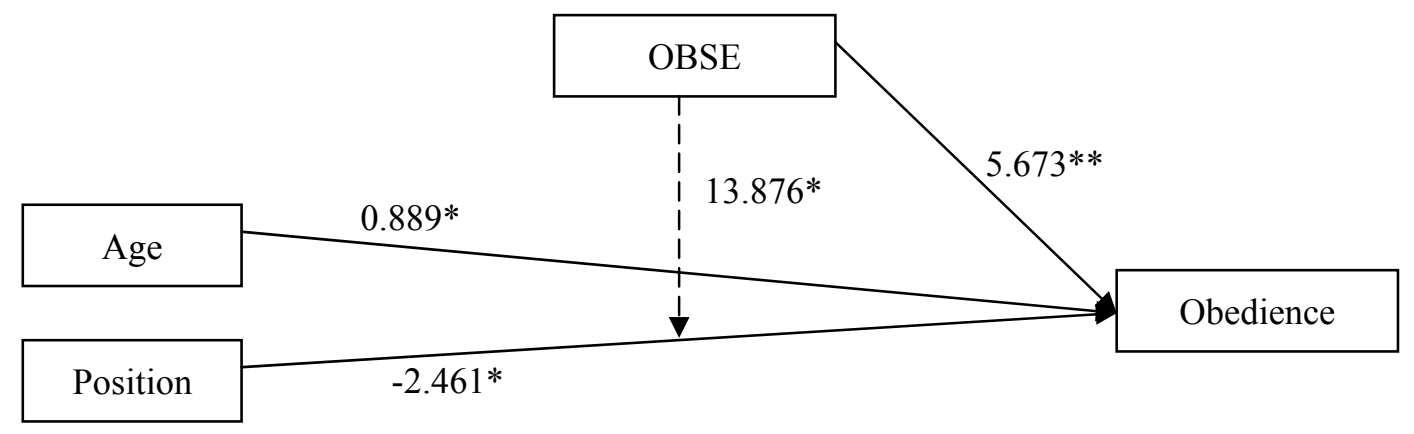

Figure 3. The resulting predictive model for Study 1

With regards to the random effects for the intercept term $\left(\pi_{00}\right)$, the value was $0.828, \chi^{2}=$ 
$19.126, p=.024$. Furthermore, the slope terms of age $\left(\pi_{11}\right)$ and position $\left(\pi_{21}\right)$ were $0.728\left(\chi^{2}=\right.$ $18.230, p=.032)$ and $3.811\left(\chi^{2}=76.315, p=.000\right)$, respectively. All were significant for this model. From this information and the random effects of the random coefficient model, it can be seen that OBSE accounted for $27.05 \%$ of the parameter variance in age and $34.13 \%$ of the parameter variance in position with respect to obedience.

Table 2. HLM results for obedience

\begin{tabular}{|c|c|c|c|}
\hline Fixed effect & Null model & $\begin{array}{c}\text { Random } \\
\text { coefficient model }\end{array}$ & $\begin{array}{c}\text { Intercepts- and } \\
\text { slopes-as-outcomes } \\
\text { model }\end{array}$ \\
\hline \multicolumn{4}{|l|}{ Within-occupation level } \\
\hline Intercept $\left(\gamma_{00}\right)$ & $\begin{array}{c}34.456^{* * *} \\
(0.411)\end{array}$ & $\begin{array}{c}34.364^{* * *} \\
(0.428)\end{array}$ & $\begin{array}{c}34.440^{* * * *} \\
(0.335)\end{array}$ \\
\hline \multirow[t]{2}{*}{ Age $\left(\gamma_{10}\right)$} & & $0.889^{*}$ & $0.925^{*}$ \\
\hline & & $(0.318)$ & $(0.316)$ \\
\hline \multirow[t]{2}{*}{ Position $\left(\gamma_{20}\right)$} & & $-2.461^{*}$ & $-2.318^{* * *}$ \\
\hline & & $(0.846)$ & $(0.702)$ \\
\hline \multicolumn{4}{|l|}{ Between-occupations level } \\
\hline $\operatorname{OBSE}\left(\gamma_{01}\right)$ & & & $5.673^{* *}(1.520)$ \\
\hline Age $\times \operatorname{OBSE}\left(\gamma_{11}\right)$ & & & $3.490(2.880)$ \\
\hline Position $\times$ OBSE $\left(\gamma_{21}\right)$ & & & $13.876^{*}(5.649)$ \\
\hline \multicolumn{4}{|l|}{ Random effect } \\
\hline Within-occupation residual & $\begin{array}{c}1.226 \\
(1.107)\end{array}$ & $\begin{array}{l}1.526 \\
(1.235)\end{array}$ & $\begin{array}{c}0.828 \\
(0.910)\end{array}$ \\
\hline Age slope & & $0.573(0.757)$ & $0.728(0.853)$ \\
\hline Position slope & & $5.785(2.405)$ & $3.811(1.952)$ \\
\hline ICC within occupation & .959 & & \\
\hline ICC between occupations & .063 & & \\
\hline $\mathrm{R}^{2}$ within occupation & & .24 & \\
\hline $\mathrm{R}^{2}$ between occupations & & & .46 \\
\hline Deviance & 2011.764 & 1989.431 & 1967.280 \\
\hline
\end{tabular}

Note: Respondents $n=349$; Occupations $n=12$.

${ }^{*} p<.05,{ }^{* *} p<.01,{ }^{* * *} p<.001$. One-tailed tests.

In Table 2, the deviance in the null model was 2011.764; the random coefficient model and intercepts- and slopes-as-outcomes model were 1989.431 and 1967.280, respectively. The deviance reduced gradually, so the results show that the random coefficient model was better than the null model, while the intercepts- and slopes-as-outcomes model was better than the random coefficient model with regards to the statistical results.

\subsection{Study 2: Loyalty as the Outcome Variable}

\subsubsection{Null Model}

In this model, loyalty was the outcome variable, and $\tau_{00}=2.072, \chi^{2}=38.243, p=.000$. The value of ICC (1) and ICC (2) of OBSE were .074 and .966. The ICC (1) value of loyalty was .084 ; indicating that $8.4 \%$ of the variance in loyalty resided between occupations, and 
$91.6 \%$ of the variance resided within occupations.

\subsubsection{Random Coefficient Model.}

$\mathrm{H} 1 \mathrm{~b}$ and $\mathrm{H} 2 \mathrm{~b}$ predicted that individual age and position would be associated with individual workers' loyalty. Similar to the random coefficient model in Study 1, Level 1 including age and position, with no predictors specified for Level 2. The two independent variables only explained $4 \%$ of the within-occupation variance. In Table 3 , age $\left(\gamma_{10}=1.254, p=0.000\right)$ and position $\left(\gamma_{20}=-2.361, p=0.008\right)$ had significantly positive and negative relationships with obedience, respectively. Therefore, $\mathrm{H} 1 \mathrm{~b}$ and $\mathrm{H} 2 \mathrm{~b}$ were supported.

The random effects were also tested. Using a chi-squared test to examine the variance component of the intercept term $\left(\pi_{00}\right)$, the value was $1.979, \chi^{2}=26.377, p=.004$. This result demonstrated that the null hypothesis should be rejected, and the occupations varied significantly in loyalty at entry into the age and position. Moreover, the slope terms of age and position were $0.022\left(\chi^{2}=4.534, p>.500\right)$ and $3.912\left(\chi^{2}=59.564, p=.000\right)$, respectively. For age, the null hypothesis was not rejected and there was no significant variation. On the contrary, for position, the null hypothesis was rejected and there was significant variation.

\subsubsection{Intercepts- and Slopes-as-Outcomes Model.}

This model was used to test H3b, H4b, and H5b. As reported in Table 3, OBSE ( $\gamma_{01}=4.492, p$ $=0.171$ ) was not significantly related to loyalty. Hence, H3b was not supported. To test H4b and $\mathrm{H} 5 \mathrm{~b}$ - whether age and position were significant associated with loyalty - the intercepts-as-outcomes model was used first. Table 3 shows that age $\left(\gamma_{10}=1.250, p=0.000\right)$

and position $\left(\gamma_{20}=-2.402, p=0.007\right)$ were positively and negatively related to loyalty. However, OBSE did not moderate the relationships between age and loyalty and position and loyalty. Therefore, $\mathrm{H} 4 \mathrm{~b}$ and $\mathrm{H} 5 \mathrm{~b}$ were not supported. The specified occupation-level variables accounted for $16 \%$ of the between-occupations variance in loyalty. The resulting model is shown in Figure 4.

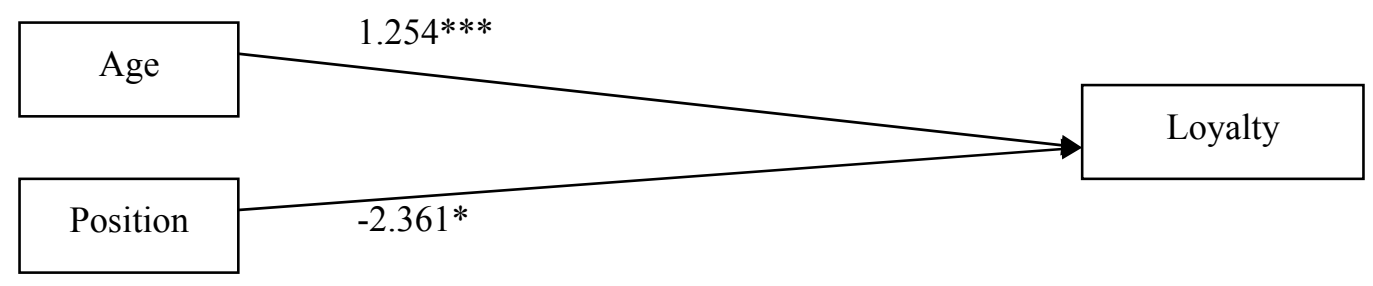

Figure 4. The resulting predictive model for Study 2.

With respect to the random effects of the intercept term $\left(\pi_{00}\right)$, the value was $1.659, \chi^{2}=$ 
$21.269, p=.012$. Furthermore, the slope terms of age $\left(\pi_{11}\right)$ and position $\left(\pi_{21}\right)$ were $0.004\left(\chi^{2}=\right.$ 4.492, $p>.500)$ and $4.540\left(\chi^{2}=61.493, p=.000\right)$, respectively. Both the intercept term and position were significant for this model, but age was not. Based on this information and from the random effects of the random coefficient model, OBSE accounted for $81.82 \%$ of the parameter variance in age and $16.05 \%$ of the parameter variance in position, with regards to loyalty.

Table 3. HLM results for loyalty

\begin{tabular}{|c|c|c|c|}
\hline Fixed effect & Null model & $\begin{array}{c}\text { Random } \\
\text { coefficient model }\end{array}$ & $\begin{array}{c}\text { Intercepts- and } \\
\text { slopes-as-outcomes } \\
\text { model }\end{array}$ \\
\hline \multicolumn{4}{|l|}{ Within-occupation level } \\
\hline Intercept $\left(\gamma_{00}\right)$ & $\begin{array}{c}32.875^{* * *} \\
(0.509)\end{array}$ & $\begin{array}{c}32.850^{* * *} \\
(0.485)\end{array}$ & $\begin{array}{c}32.879^{* * *} \\
(0.429)\end{array}$ \\
\hline Age $\left(\gamma_{10}\right)$ & & $\begin{array}{l}1.254^{* * *} \\
(0.182)\end{array}$ & $\begin{array}{l}1.250^{* * *} \\
(0.182)\end{array}$ \\
\hline Position $\left(\gamma_{20}\right)$ & & $\begin{array}{l}-2.361^{* *} \\
(0.720)\end{array}$ & $\begin{array}{l}-2.402^{* *} \\
(0.689)\end{array}$ \\
\hline \multicolumn{4}{|l|}{ Between-occupations level } \\
\hline $\operatorname{OBSE}\left(\gamma_{01}\right)$ & & & $4.492(3.046)$ \\
\hline $\operatorname{Age} \times \operatorname{OBSE}\left(\gamma_{11}\right)$ & & & $2.007(1.360)$ \\
\hline Position $\times$ OBSE $\left(\gamma_{21}\right)$ & & & $-0.479(6.008)$ \\
\hline \multicolumn{4}{|l|}{ Random effect } \\
\hline Within-occupation residual & $\begin{array}{l}2.072 \\
(1.440)\end{array}$ & $\begin{array}{l}1.980 \\
(1.408)\end{array}$ & $\begin{array}{c}1.659 \\
(1.288)\end{array}$ \\
\hline Age slope & & $0.022(0.147)$ & $0.004(0.061)$ \\
\hline Position slope & & $3.912(1.980)$ & $4.540(2.131)$ \\
\hline ICC within occupation & .970 & & \\
\hline ICC between occupations & .084 & & \\
\hline $\mathrm{R}^{2}$ within occupation & & .04 & \\
\hline $\mathrm{R}^{2}$ between occupations & & & .16 \\
\hline Deviance & 2089.361 & 2059.883 & 2041.750 \\
\hline
\end{tabular}

Note: Respondents $n=349$; Occupations $n=12$.

${ }^{*} p<.05,{ }^{* *} p<.01,{ }^{* * *} p<.001$. One-tailed tests.

In Table 3, the deviance in the null model was 2089.361; in the random coefficient model, it was 2059.883; and in the intercepts- and slopes-as-outcomes model, it was 2041.750. The deviance reduced gradually, and this meant that the random coefficient model was better than the null model, while the intercepts- and slopes-as-outcomes model was better than the random coefficient model, in terms of the statistical results obtained.

\section{Discussion}

The aim of this study was to investigate female workers and understand the effects of their ages and positions on three factors of OCB, where OBSE was the moderator. HLM was used, and the results obtained were as follows. ICC (1), participation, did not achieve the acceptable standard, so H1c, H2c, H3c, H4c, and H5c could not be tested. The results showed that all the hypotheses in Study 1 were supported, except for H4. Additionally, in Study 2, 
$\mathrm{H} 1 \mathrm{~b}$ and $\mathrm{H} 2 \mathrm{~b}$ were supported, but $\mathrm{H} 3 \mathrm{~b}, \mathrm{H} 4 \mathrm{~b}$ and $\mathrm{H} 5 \mathrm{~b}$ were not. These results mean that age and position directly predict loyalty, and that OBSE does not predict loyalty and is not influenced by age and position with respect to loyalty.

The results demonstrate that obedience and loyalty are related to age and position. However, in both Study 1 and Study 2, the results show that age positively predicts obedience and loyalty, and position negatively predicts obedience and loyalty. The results regarding the relationship between age and obedience and loyalty support those found by Wagner and Rush (2000).

According to Bedeian et al. (1992) and Carbery et al. (2003), older workers are more satisfied, because they are able to achieve more of their goals through work and may have longer tenures, thus experiencing fewer turnover cognitions. The results of this study are similar to those of the studies mentioned above, and demonstrate that workers' age positively predicts obedience and loyalty. In other words, when age increases, the degrees of obedience and loyalty also increase.

The studies to date about position in relation to OCB are not sufficient, so the main contribution of this study is to discuss this issue. The results of this study indicate that managers have lower obedience and loyalty levels than non-managers. The reason for this is that the evaluation of subordinates' performance is related to OCB. Recent research has also advocated that managers' performance ratings are influenced by OCB. Additionally, employees who have higher levels of OCB are more likely to receive promotions than employees with lower levels of OCB (Hui, Lam, \& Law, 2000). Spector et al. (2010) also indicated that supervisors had stronger negative counterproductive work behaviour - OCB correlations than other employees. Lovell et al. (1999) demonstrated that citizenship behaviours are as important as objective measures of productivity in determining a subordinate's performance rating; however, a manager must not only consider OCB when assessing their subordinates' performance. The above perspectives support the results of this study. Hence, managers are less likely to have high levels of OCB compared to non-managers.

In Study 1, OBSE was found to predict obedience, however it could not predict loyalty in Study 2. Because obedience and loyalty belong to OCB, the results of this study cannot fully support the perspective of Bowling et al. (2010). That is to say, workers who consider themselves to be capable, significant, and worthy as organizational members (Pierce \& Gardner, 2009) obey the rules and regulations of the organization, but do not feel a strong need to follow leaders or protect their organization.

This study examined OBSE's cross-level interactions with age and position in predicting OCB. However, it was found that OBSE only moderates the relationship between position and OCB. Furthermore, the present study explored the interaction between position and OBSE, finding that there was a significant and negative relationship between position and obedience. These findings suggest that OBSE is an important variable that has a meaningful effect on individual behaviour. According to the results of this study, obedience can be enhanced when a position is accompanied by reinforcement of OBSE. 


\section{Conclusions and Implications}

The research results of the present study are important for theory and practice. This is because most studies test OCB as a whole, whereas this study discusses the elements of OCB. OCB comprises three elements, and each element represents a different concept. Thus, this study treated obedience and loyalty as dependent variables in Study 1 and 2, respectively, and then tested whether the same independent variables and moderators have the same effects on obedience and loyalty. The results show that age is positively related to obedience and loyalty, and position is negatively related to both, but that OBSE only moderates the relationship between position and obedience.

The results of this study have implications for companies. OCB was important within organizations, because it was associated with some critical factors, such as managers' evaluations of performance, organizational effectiveness, and job satisfaction (Foote \& Tang, 2008; Torlak \& Koc, 2007). Moreover, the above factors are important for survival and success of organizations. This study found that increased age and lower position were related to higher obedience and loyalty. Employees with higher obedience and loyalty have higher identity for their organizations, and then achieve shared goal and increase organizational competitive advantage.

In addition, this study provides several recommendations and managerial implications. First, employers should not seek solely to employ younger workers and dismiss those who are older, since older workers are often more loyal to the job and the organization. This may be because younger workers have more opportunities to change or transfer jobs compared to older workers, and younger workers are less concerned with how their employment will end (Bal, De Lange, Jansen, \& Van Der Velde, 2008). Thus, the results of this study showed that older workers have higher obedience and loyalty than younger workers, and this concept is consistent with the above statement. Second, this study found that OBSE only positively influenced obedience, and this result followed cognitive consistency theory. Therefore, this study concluded that employees considered they were valuable, worthwhile, and effectual members of their organizations, and they were more likely to follow the rules of their employing organizations. Third, many studies have discussed OCB, but not have explored the contents of each element. This study investigated obedience and loyalty, and proved that OBSE only influenced obedience and moderated the relationship between position and obedience. Fourth, although obedience and loyalty belong to OCB, the results of this study proved that OCB could not contain both concepts completely, and the research results (H3a and $\mathrm{H} 3 \mathrm{~b}, \mathrm{H} 5 \mathrm{a}$ and $\mathrm{H} 5 \mathrm{~b}$ ) confirmed this concept. Fifth, many female workers cannot have high position within organizations, because they often confront the conflict between work and family. However, this study proved that they could find the balance point between work and family, and when female workers considered that they were important for organizations, they could follow the rules of their organizations. Moreover, the importance of female workers in organizations was low or middle, the obedience of managers and non-manager had not a great difference, but when the importance of them in organizations was high, managers had higher obedience than non-managers. Nevertheless, the loyalty of workers did not influenced by the importance of them in organizations. Thus, organizations should 
improve employees' job satisfaction, and the effective methods included employee empowerment, teamwork, and employee compensation (Jun, Cai, \& Shin, 2006), and then the employees' loyalty can be fostered. Therefore, we concluded that discussing obedience and loyalty instead of OCB was justified. The most important was that several studies indicated that OCB and OBSE were the critical issues for organizations and workers. OCB not only contributed to the effective functioning of an organization, but also improved the interaction between employee and customer, and then fostered service climate and customer loyalty. What's more, the significantly positive correlation existed between OCB and employee's job satisfaction (Nadiri \& Tanova, 2010). Additionally, OBSE was positive related to employee's job satisfaction, and played an important role in on-the-job development (Gardner et al., 2004). So, OCB and OBSE were important for organizations and employees. Organizations should pay more attention to all workers and provide them more opportunity to express their thoughts and ideas. Moreover, organizations use positive reinforcement (e.g. higher pay, well-being, good workplace and organizational climate) to encourage all workers to show OCB and OBSE, and then facilitate employees' performance and organizational competitiveness.

The limitations of this study should be noted. First, this study was based on data collected from 12 occupations. Although this study desired to understand the common situation for female workers' age, position, and OBSE on OCB, this study could not investigate all occupations in Taiwan. Second, this study could not investigate an equal number of female workers in each occupation, so this might cause the bias results. Third, it was difficult to find participants in Taiwan who answered all of the questions in the questionnaire. This situation also gives rise to the fourth limitation, which was that because HLM cannot handle missing data in a questionnaire, some data had to be removed from this study. Fifth, OCB and OBSE are self-reported measures, which may mean that common method bias was generated, and that the responses may not have been an exact reflection of reality (Crampton \& Wagner, 1994; Liao \& Chuang, 2004). Moreover, it would be useful for future research to discuss whether gender influences OCB where OBSE is the moderator. This study is certain that obedience and loyalty belong to OCB, but OBSE only influenced obedience. Hence, this study considered that obedience, loyalty, and participant have different concepts. Based on this study, future research will employ the three elements of OCB to explore the development path of OCB and will provide the research results for managers in practice.

\section{References}

Anker, R. (1997). Theories of occupational segregation by sex: an overview. International Labour Review, 136, 315-339.

Bal, P. M., De Lange, A. H., Jansen, P. G. W., \& Van Der Velde, M. E. G. (2008). Psychological contract breach and job attitudes: a meta-analysis of age as a moderator. Journal of Vocational Behavior, 72, 143-158.

Bedeian, A. G., Ferris, G. R., \& Kacmar, K. M. (1992). Age, tenure, and job satisfaction: a tale of two perspectives. Journal of Vocational Behavior, 40, 33-48. 
Bowler, W. M., Halbesleben, J. R. B., \& Paul, J. R. B. (2010). If you're close with the leader, you must be a brownnose: The role of leader-member relationships in follower, leader, and coworker attributions of organizational citizenship behavior motives. Human Resource Management Review, 20, 309-316.

Bowling, N. A., Eschleman, K. J., Wang, Q., Kirkendall, C., \& Alarcon, G. (2010). A meta-analysis of the predictors and consequences of organization-based self-esteem. Journal of Occupational and Organizational Psychology, 83, 601-626.

Carbery, R., Garavan, T. N., O’Brien, F., \& McDonnell, J. (2003). Predicting hotel managers'turnover cognitions. Journal of Managerial Psychology, 18, 649-679.

Chao, C. C. (2011). Climbing the Himalayas: a cross-cultural analysis of female leadership and glass ceiling effects in non-profit organizations. Leadership \& Organization Development Journal, 32, 760-781.

Chen, Z. X., Aryee, S., \& Lee, C. (2005). Test of a mediation model of perceived organizational support. Journal of Vocational Behavior, 66, 457-470.

Chiang, C. F., \& Hsieh, T. S. (2012). The impacts of perceived organizational support and psychological empowerment on job performance: the mediating effects of organizational citizenship behavior. International Journal of Hospitality Management, 31, 180-190.

Colley, L. (2011). Not codgers in cardigans! Female workforce participation and ageing public services. Gender, Work and Organization. http://dx.doi.org/10.1111/j.1468-0432.2011.00582.x

Crampton, S. M., \& Wagner, J. A. (1994). Percept-percept inflation in microorganizational research: an investigation of prevalence and effect. Journal of Applied Psychology, 79, 67-76.

Dimitriades, Z. S. (2007). The influence of service climate and job involvement on customer-oriented organizational citizenship behavior in Greek service organizations: a survey. Employee Relations, 29, 469-491.

Foote, D. A., \& Tang, T. L. P. (2008). Job satisfaction and organizational citizenship behavior (OCB): Does team commitment make a difference in self-directed teams? Management Decision, 46, 933-947.

Gardner, D. G., Van Dyne, L., \& Pierce, J. L. (2004). The effects of pay level on organization-based self-esteem and performance: a field study. Journal of Occupational and Organizational Psychology, 77, 307-322.

Gavin, M. B., \& Hofmann, D. A. (2002). Using hierarchical linear modeling to investigate the moderating inf luence of leadership climate. The Leadership Quarterly, 13, 15-33.

Gentry, W. A., \& Martineau, J. W. (2010). Hierarchical linear modeling as an example for measuring change over time in a leadership development evaluation context. The Leadership Quarterly, 21, 645-656.

Haslam, S. A., \& Ryan, M. K. (2008). The road to the glass cliff: differences in the perceived 
suitability of men and women for leadership positions in succeeding and failing organizations. The Leadership Quarterly, 19, 530-546.

Hui, C., Lam, S. K., \& Law, K. S. (2000). Instrumental values of organizational citizenship behavior for promotion: a field quasi-experiment. Journal of Applied Psychology, 85, $822-828$.

Hui, C., Lee, C., \& Niu, X. (2010). The moderating effects of polychronicity and achievement striving on the relationship between task variety and organization-based self-esteem of mid-level managers in China. Human Relations, 63, 1395-1416.

Jun, M., Cai, S., \& Shin, H. (2006). TQM practice in maquiladora: Antecedents of employee satisfaction and loyalty. Journal of Operations Management, 24, 791-812.

Kang, B., Twigg, N. W., \& Hertzman, J. (2010). An examination of social support and social identity factors and their relationship to certified chefs' burnout. International Journal of Hospitality Management, 29, 168-176.

Kim, S. (2006). Public service motivation and organizational citizenship behavior in Korea. International Journal of Manpower, 27, 722-740.

Lapierre, L. M., Bonaccio, S., \& Allen, T. D. (2009). The separate, relative, and joint effects of employee job performance domains on supervisors' willingness to mentor. Journal of Vocational Behavior, 74, 135-144.

Liao, H., \& Chuang, A. (2004). A multilevel investigation of factors influencing employee service performance and customer outcomes. Academy of Management Journal, 47, 41-58.

Liu, Y. (2009). Perceived organizational support and expatriate organizational citizenship behavior: the mediating role of affective commitment towards the parent company. Personnel Review, 38, 307-319.

Lovell, S. E., Kahn, A. S., Anton, J., Davidson, A., Dowling, E., Post, D., et al. (1999). Does gender affect the link between organizational citizenship behavior and performance evaluation? Sex Roles, 41, 469-478.

Nadiri, H., \& Tanova, C. (2010). An investigation of the role of justice in turnover intentions, job satisfaction, and organizational citizenship behavior in hospitality industry. International Journal of Hospitality Management, 29, 33-41.

Panaccio, A., \& Vandenberghe, C. (2011). The relationships of role clarity and organization-based self-esteem to commitment to supervisors and organizations, and turnover intentions. Journal of Applied Social Psychology, 41, 1455-1485.

Pierce, J. L., \& Gardner, D. G. (2009). Relationships of personality and job characteristics with organization-based self-esteem. Journal of Managerial Psychology, 24, 392-409.

Pierce, J. L., Gardner, D. G., Cummings, L. L., \& Dunham, R. B. (1989). Organization-based self-esteem: construct definition,measurement, and validation. The Academy of Management Journal, 32, 622-648. 
Ross-Smith, A., \& Huppatz, K. (2010). Management, women and gender capital. Gender, Work and Organization, 17, 547-566.

Sekiguchi, T., Burton, J. P., \& Sablynski, C. J. (2008). The role of job embeddedness on employee performance: the interactive effects with leader-member exchange and organization-based self-esteem. Personnel Psychology, 61, 761-792.

Soubelet, A. (2011). Age-cognition relations and the personality trait of Conscientiousness. Journal of Research in Personality, 45, 529-534.

Spector, P. E., Bauer, J. A., \& Fox, S. (2010). Measurement artifacts in the assessment of counterproductive work behavior and organizational citizenship behavior: do we know what we think we know? Journal of Applied Psychology, 95, 781-790.

Tang, T. L. P., \& Ibrahim, A. H. S. (1998). Antecedents of organizational citizenship revisited: public personnel in the United States and in the Middle East. Public Personnel Management, $27,529-550$.

Tang, T. V., \& Tang, Y. Y. (2011). Promoting service-oriented organizational citizenship behaviors in hotels: the role of high-performance human resource practices and organizational social climates. International Journal of Hospitality Management. http://dx.doi.org/10.1016/j.ijhm.2011.10.007.

Torlak, O., \& Koc, U. (2007). Materialistic attitude as an antecedent of organizational citizenship behavior. Management Research News, 30, 581-596.

Van Dyne, L., Graham, J. W., \& Graham, R. M. (1994). Organizational citizenship behavior: construct redefinition, measurement, and validation. Academy of Management Journal, 37, 765-802.

Van Dyne, L., Vandewalle, D., Kostova, T., Latham, M. E., \& Cummings, L. L. (2000). Collectivism, propensity to trust and self-esteem as predictors of organizational citizenship in a non-work setting. Journal of Organizational Behavior, 21, 3-23.

Wagner, S. L., \& Rush, M. C. (2000). Altruistic organizational citizenship behavior: Context, disposition, and age. The Journal of Social Psychology, 140, 379-391.

Widmer, P. S., Semmer, N. K., Kälin, W., Jacobshagen, N., \& Meier, L. L. (2011). The ambivalence of challenge stressors: time pressure associated with both negative and positive well-being. Journal of Vocational Behavior. http://dx.doi.org/10.1016/j.jvb.2011.09.006

Zacher, H., Heusner, S., Schmitz, M., Zwierzanska, M. M., \& Frese, M. (2010). Focus on opportunities as a mediator of the relationships between age, job complexity, and work performance Journal of Vocational Behavior, 76, 374-386. 